\title{
METHICILLIN RESISTANCE STAPHYLOCOCCUS AUREUS (MRSA) FROM CSOM IN A TERTIARY CARE HOSPITAL
}

\section{Microbiology}

Dr.A.V.Kavitha

\section{Dr. Thyagarajan} Ravinder*

Post Gradate, Department of Microbiology, Government Kilpauk Medical College and Hospital, Kilpauk, Chennai.

M.D Microbiology, Professor, Department of Microbiology, Government Kilpauk Medical College and Hospital, Kilpauk, Chennai. *Corresponding Author

Dr. Radhika
Katragadda

M.D Microbiology, Head of the Department, Department of Microbiology, Government Kilpauk Medical College and Hospital, Kilpauk, Chennai
Dr. Leela Vajravelu M.D Microbiology, Professor, Department of Microbiology, Government Kilpauk Medical College and Hospital, Kilpauk, Chennai.

\section{ABSTRACT}

Introduction:Chronic Suppurative Otitis Media (CSOM) is one of the major cause of preventable hearing loss if treated promptly. Emergence of resistant strains in the world is of great concern. The aim of the present study was to determine the aetiology and antibiotic sensitivity pattern of bacterial isolates from CSOM cases with special emphasis on Methicillin Resistant Staphylococcus aureus.

Materials and methods: Ear swabs ear swabs collected from 212 patients attending otorhinolaryngology department, GKMC, Chennai was processed in Microbiology lab. Direct gram staining was done and then inoculated into Blood, MacConkey and Nutrient agar. Bacterial identification was done using standard microbiological techniques. Antibiotic susceptibility was done by Kirby Bauer disc diffusion technique. Methicillin Resistant Staphylococcus aureus (MRSA) was detected by Cefoxitin disc diffusion method as per CLSI guidelines.

Results: 60 Gram positive bacteria were isolated from collected ear swabs. Staphylococcus aureus 46(26.59\%) was the most common bacteria among Gram positive organism followed by CONS 9(5.20\%) and Enterococci 5(2.89\%). Among Staphylocoocus aureus, 41(89.13\%) and 40(86.95\%) showed sensitivity to amikacin and ofloxacin respectively. All the Gram Positive cocci were 100\% sensitive to Vancomycin and Linezolid. 19.53\% were confirmed as MRSA by cefoxitin disc diffusion method.

Conclusion: Microbial pattern can vary in different location in different periods of time. Hence knowledge of appropriate aetiology and antimicrobial resistance pattern of CSOM helps in rational use of antibiotics and control of drug resistance.MRSA is emerging as an important pathogen in CSOM. Empirical antibiotics should be directed to gram positives, and especially, MRSA should be taken into consideration.

\section{KEYWORDS}

Chronic suppurative otitis media (CSOM), Staphylococcus aureus, MRSA

\section{INTRODUCTION}

Chronic suppurative otitis media (CSOM) is one of the most common cause of preventable hearing loss in both adults and children mainly in developing countries like India. Around $90 \%$ of the disease burden is prevalent in Africa, South-east Asia and Western Pacific regions and some ethnic minorities present in the Pacific Rim ${ }^{1}$. CSOM is infrequent in countries like Americas, Australia, Europe, and the Middle East. According to a recent survey from a school in Tamilnadu, India (7.8\%) has the highest no of CSOM cases among South-East Asian countries which is comparably lower than earlier estimates $(16 \%-34 \%)^{1}$. In view of burden of CSOM, World Health Organization (WHO) has classified India in highest $(>4 \%)$ prevalence group ${ }^{2}$. Several organisms have been implicated in the etiology of CSOM, posing a challenge to the management. Commonly isolated bacteria include Staphylococcus aureus (Methicillin resistant (MRSA) and methicillin-sensitive [MSSA]), Pseudomonas, Proteus, Coagulase-negative Staphylococcus, Enterococcus, and Anaerobes (including Peptostreptococcus, Prevotella, Fusobacterium, Bacteroides and Porphyromonas $)^{3}$.Typically, viral infection of the upper respiratory tract precedes the disease, but soon the conditions are favourable for the middle ear to be invaded by pyogenic organisms ${ }^{4}$. The infection from middle ear can spread to adjacent structures such as facial nerve, mastoid, labyrinth, lateral sinus, meninges and brain which can lead to facial nerve paralysis, mastoid abscess, labyrintitis, lateral sinus thrombosis and meningitis respectively ${ }^{[5,6]}$. The indiscriminate and haphazard use of antibiotics in CSOM have resulted in persistence of low-grade infections. Persistently changing microbiological flora with the introduction of new antimicrobials has made timely evaluation of bacterial flora of CSOM and their antibiotic resistance pattern. This evaluation will contribute to rational usage of antibiotics, success of treatment and prevention of the complications in CSOM patients. . A substantial proportion of outpatient strains of MRSA from ear discharge has been found in otolaryngeal practices. According to previous reports, MRSA infection in preoperative ear discharge has led to higher rates of postoperative otorrhoea and reperforation after tympanomastoid surgeries ${ }^{7}$. Therefore, early identification and detection of MRSA is essential prior to treatment, as cases with these infections are resistant to routine beta-lactam antibiotics and
Penicillin. Knowledge on the local incidence as well as spectrum of bacteria present and their antimicrobial susceptibility patterns is imperative for effective empirical treatment as well as contributing to the general understanding of the disease. The aim of this study was to identify MRSA isolates with their antibiotic pattern from ear discharge in patients clinically diagnosed as CSOM attending otorhinolaryngology outpatient clinics.

\section{MATERIALSAND METHODS:}

This prospective study was done on patients clinically diagnosed as CSOM attending ENT OPD, Government Kilpauk Medical College and Hospital from January 2013 to August 2014. Samples were transported and further processed in Department of Microbiology, Government Kilpauk Medical College and Hospital, Chennai. All age groups and both sexes with no previous antibiotic (both systemic and topical) treatment taken for minimum of 1 week prior to sample collection were included in this study. Patients having pathogens other than bacteria, patients with other middle ear infections, patients with discharge less than 3 weeks were excluded.

After obtaining informed content from the patient and with aseptic precautions, discharge from middle ear were collected using two sterile cotton swabs. One swab was used for direct gram stain smear. Another swab was inoculated into Nutrient agar, 5\% Sheep blood agar and Mac Conkey agar and further incubated at $37^{\circ} \mathrm{c}$ for $24 \mathrm{hrs}$. Aerobic bacteria grown were identified upto species level using standard microbiological techniques. Antibiotic sensitivity testing was performed on Mueller Hinton agar using Kirby Bauer disk diffusion method $^{8}$. Interpretation of the results was done by measuring the size of the zone of inhibition according to CLSI guidelines ${ }^{9}$. Escherichia coliATCC 25922, Pseudomonas aeruginosa - ATCC 27853, Staphylococcus aureus - ATCC 25923 were used as quality control strains.

\section{Antibiotics used for Gram positive bacteria:}

Amoxicillin, Erythromycin, Doxycycline, Cephalexin, Cefotaxime, Amikacin, Gentamicin, Ciprofloxacin, Ofloxacin, Co-trimaxazole, Vancomycin, Linezolid, Cefoxitin were tested for Staphylococcus 
aureus. Amoxicillin, Erythromycin, Doxycycline, Cephalexin, Cefotaxime, Amikacin, Gentamicin, Ciprofloxacin, Ofloxacin, Cotrimaxazole, Vancomycin, Linezolid, Cefoxitin were tested for Coagulase negative Staphylococcus species (CoNS). Erythromycin, Doxycycline, Amikacin, High level Gentamicin, Ciprofloxacin, Ofloxacin, Co-trimaxazole, Vancomycin, Linezolid were tested for Enterococcus faecalis.

\section{Cefoxitin disc diffusion test to detect mrsa ${ }^{10}$}

The test was performed by placing $30 \mu \mathrm{g}$ of cefoxitin disc in the Mueller Hinton Agar plate without $\mathrm{NaCl}$ supplementation inoculated with test organism. The plate was kept in incubator at a temperature of $37^{\circ} \mathrm{c}$. The zone of inhibition was determined after $24 \mathrm{hrs}$ and the zone size was interpreted as Susceptible: $\geq 21 \mathrm{~mm}$ Resistant: $\leq 21 \mathrm{~mm}$ (Figure no.1)

\section{RESULT}

In our study, 60 gram positive bacteria was isolated from ear swabs collected in patients clinically diagnosed as CSOM. The mean age group was patients in the age group of 21- 30 years. Males were predominant than females in our study (Table no.1). 36(60\%) had annual income of less than 50000 whereas only $10(10 \%)$ had the annual income of $\geq 100000$. About $10(10 \%)$ were illiterates and $36(60 \%)$ did not have regular ear cleaning habits (Table no.2).

Out of 60 Gram positive bacteria isolated, Staphylococcus aureus was the most common organism isolated among the Gram positive cocci followed by Coagulase negative Staphylococcus and Enterococcus species. Other Gram Negative organisms isolated were Pseudomonas aeruginosa, Klebsiella pneumoniae, Proteus mirabilis and Escherichia coli.

Staphylococcus aureus showed $89.13 \%$ and $86.95 \%$ sensitivity to amikacin and Ofloxacin respectively. Coagulase Negative Staphylococcus showed $88.88 \%$ sensitivity to amikacin and Ofloxacin respectively. All the Gram Positive cocci were $100 \%$ sensitive to Vancomycin and Linezolid. Out of 5 Enterococcus faecalis, $80 \%$ were sensitive to both Ofloxacin and amikacin (Table no.3).

By cefoxitin disc diffusion method, Out of 46 Staphylococcus aureus, 9(19.56\%) were Methicillin Resistant Staphylococcus aureus. Out of 9 Coagulase Negative Staphylococcus isolated, 2(22.22\%) were Methicillin Resistant CONS (Figure no.2).

The antimicrobial pattern of MRSA and MSSA strains is shown in (Table.no.4) All MRSA and MSSA isolates were 100\% sensitive to Vancomycin and Linezolid. Increase resistance was seen only to amoxycillin 4(44\%).

\section{DISCUSSION}

CSOM is a major global health problem in children and adults, especially in developing nations resulting in chronic hearing loss and is responsible for significant morbidity and mortality due to complications. According to a report by WHO, India belongs to the highest ( $>4 \%$ ) CSOM prevalent countries. Incidence of complications due to CSOM is low if treated promptly. Hence it is essential to start treatment early and effectively to avoid such complications. Knowledge of the microorganism pattern and their antibiotic sensitivity is then essential to allow for effective and cost-saving treatment.

In our study, the second most common organism isolated was Staphylococcus aureus in $26.5 \%$ cases. Similar rate of isolation were reported in Malkappa et $\mathrm{al}^{11}$, Sahu MC et $\mathrm{al}^{12}$, Sawaraj S et al ${ }^{13}$ and Garima et $\mathrm{al}^{14}$. The ubiquitous nature and higher carriage of resistant strains in the external auditory canal and upper respiratory tract attributes to increased frequency of middle ear infections with Staphylococcus aureus.

Staphylococcus aureus was found to be resistant to Penicillin followed by co-trimaxazole and most sensitive to Ofloxacin and amikacin. Amikacin was found to be effective against Staphylococcus aureus followed by Ofloxacin. This was in concordance with Prachita et $\mathrm{al}^{15}$, Prakash R et $\mathrm{al}^{16}$, and Prakash $\mathrm{M}$ et $\mathrm{al}^{17}$. All Staphylococcus aureus were sensitive to Vancomycin and Linezolid. Out of 9 CONS, $8(88.88 \%)$ were sensitive to Ofloxacin and amikacin. Out of 5 Enterococcus faecalis, $80 \%$ were sensitive to both Ofloxacin and amikacin.
Presently, MRSA is also one of the predominant pathogen in otologic diseases. MRSA were first identified in $1961^{18}$. From then onwards, the proportion of isolation of nosocomial MRSA has increased from $2 \%$ in 1974 to $50 \%$ in 1997 around the world ${ }^{19}$. There has been a steady increase in the number of cases of MRSA otorrhoea also ${ }^{(20-22)}$. Hence it is very important to diagnose MRSA infection, and the susceptibility to antimicrobial agents to initiate prompt therapy, control and preventive measures. In this study, out of 46 Staphylococcus aureus, 9(19.56\%) were found to be Methicillin resistant (MRSA). This finding was concordant with Prachita et al ${ }^{15}$, and Lakshmi et al. Our study had lower incidence of MRSA compared to other studies like Patigaroo et $\mathrm{al}^{20}$ and Manjula et $\mathrm{al}^{21}$ which showed $40 \%-60 \%$ MRSA. Lower incidence of MRSA could be due to less hospitalisation, underutilization of antibiotics in government hospitals leading to lower selection pressure for MRSA. Out of 9 CONS, 2(22.22\%) were resistant to Methicillin (MRCONS).

\section{CONCLUSION}

Staphylococcus aureus was the second most common organism followed by Pseudomonas aeruginosa in our hospital. Amikacin was found to be effective against both MSSA and MRSA. Postoperative complication and revision operation rate are more in MRSA infection which directly influence the rate of hearing improvement and tympanic membrane graft success. Hence, it is imperative in early diagnosis of MRSA infection. Appropriate knowledge of aetiology and antimicrobial resistance pattern of CSOM in every hospital is necessary to prevent irrational use of antibiotics and resistance. The antibiotic susceptibility patterns must be continuously and periodically evaluated to decrease the risk of resistant strains. Also patient should be counselled and reassured on compliance of antibiotics and hygienic measures to avoid further antibiotic resistance.

\section{Table 1: Gender distribution $(\mathrm{n}=60)$}

\begin{tabular}{|l|l|}
\hline Gender & Percentage \\
\hline Male & $35(58.4 \%)$ \\
\hline Female & $25(41.6 \%)$ \\
\hline
\end{tabular}

Table 2: Risk factors associated with $\operatorname{CSOM}(n=60)$

\begin{tabular}{|l|l|}
\hline Risk Factors & $\%$ \\
\hline Annual Income of self/ parents \\
\hline$\geq 100000$ & $10(10 \%)$ \\
\hline $100000-50000$ & $14(23.33 \%)$ \\
\hline$\leq 50000$ & $36(60 \%)$ \\
\hline Education of self/parents & \multicolumn{2}{|l|}{} \\
\hline Illiterate & $10(10 \%)$ \\
\hline SSC \& below & $29(48.33 \%)$ \\
\hline HSC \& Above & $21(35 \%)$ \\
\hline Habit of ear cleaning & $36(60 \%)$ \\
\hline no habit & $24(40 \%)$ \\
\hline cleans ear
\end{tabular}

Table No: 3-Antibiotic Sensitivity Of Gram Positive Isolates (n=60).

\begin{tabular}{|l|l|l|l|}
\hline Antibiotics & $\begin{array}{l}\text { Staphylococcus } \\
\text { aureus(n=46) }\end{array}$ & $\begin{array}{l}\text { Coagulase } \\
\text { Negative } \\
\text { Staphylococcus } \\
\text { aureus(n=9) }\end{array}$ & $\begin{array}{l}\text { Enterococcus } \\
\text { faecalis(n=5) }\end{array}$ \\
\hline Amoxycillin & $11(23.91 \%)$ & $3(33.33 \%)$ & NT \\
\hline Erythromycin & $31(67.39 \%)$ & $5(55.55 \%)$ & $2(40 \%)$ \\
\hline Doxycycline & $34(73.91 \%)$ & $7(77.77 \%)$ & $3(60 \%)$ \\
\hline Cephalexin & $33(71.73 \%)$ & $6(66.66 \%)$ & NT \\
\hline Cefotaxime & $40(86.95 \%)$ & $8(88.88 \%)$ & NT \\
\hline Amikacin & $41(89.13 \%)$ & $8(88.88 \%)$ & $4(80 \%)$ \\
\hline Gentamicin & $29(63.04 \%)$ & $6(66.66 \%)$ & $2(40 \%)$ \\
\hline Ciprofloxacin & $28(60.86 \%)$ & $5(55.55 \%)$ & $2(40 \%)$ \\
\hline Ofloxacin & $40(86.95 \%)$ & $8(88.88 \%)$ & $4(80 \%)$ \\
\hline Co-trimaxazole & $20(43.44 \%)$ & $4(44.44 \%)$ & $2(40 \%)$ \\
\hline Vancomycin & $46(100 \%)$ & $9(100 \%)$ & $5(100 \%)$ \\
\hline Linezolid & $46(100 \%)$ & $9(100 \%)$ & $5(100 \%)$ \\
\hline Cefoxitin & $9(19.56 \%)$ & $2(22.22 \%)$ & - \\
\hline
\end{tabular}

Table No 4: Antibiotic Sensitivity Pattern of MRSA and MSSA

\begin{tabular}{|l|l|l|}
\hline Antibiotics & $\begin{array}{l}\text { MSSA } \\
(\mathbf{n = 3 7 )}\end{array}$ & $\begin{array}{l}\text { MRSA } \\
(\mathbf{n = 9})\end{array}$ \\
\hline Amoxycillin & $6(16.21 \%)$ & $5(55.55 \%)$ \\
\hline Erythromycin & $23(62.16 \%)$ & $8(88.88 \%)$ \\
\hline
\end{tabular}




\begin{tabular}{|l|l|l|}
\hline Doxycycline & $26(70.27 \%)$ & $8(88.88 \%)$ \\
\hline Cephalexin & $26(70.27 \%)$ & $7(77.77 \%)$ \\
\hline Cefotaxime & $31(83.78 \%)$ & $9(100 \%)$ \\
\hline Amikacin & $32(86.48 \%)$ & $9(100 \%)$ \\
\hline Gentamicin & $22(59.45 \%)$ & $7(77.77 \%)$ \\
\hline Ciprofloxacin & $21(56.75 \%)$ & $7(77.77 \%)$ \\
\hline Ofloxacin & $34(91.89 \%)$ & $6(66.66 \%)$ \\
\hline Co-trimaxazole & $14(37.83 \%)$ & $6(66.66 \%)$ \\
\hline Vancomycin & $37(100 \%)$ & $9(100 \%)$ \\
\hline Linezolid & $37(100 \%)$ & $9(100 \%)$ \\
\hline
\end{tabular}

\section{FIGURE NO: 1}

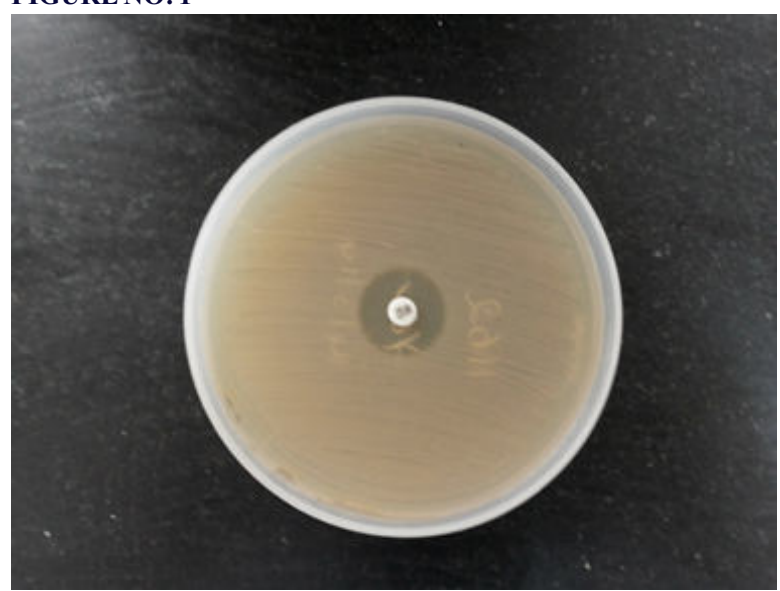

Figure No.1 - Cefoxitin disc diffusion test for detection of MRSA Zone diameter $\leq 21 \mathrm{~mm}-$ MRSA

\section{FIGURE NO: 2}

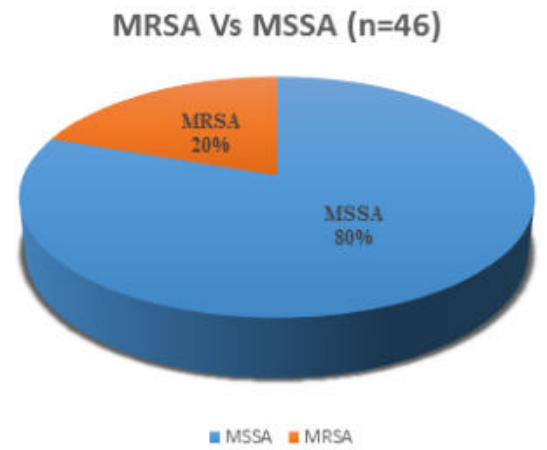

Figure No.2 - Distribution of MRSA and MSSA.

\section{REFERENCES}

[1] World Health Organisation. Chronic suppurative otitis media: burden of illness and morld Health Organisation. Chronic suppurative otitis media:

[2] Ruby N, Mohammad KF, Ruchi G, et al. Bacterial profile and antibiotic sensitivity pattern of CSOM patient in Mewat region. JEBMH 2015;2(61):9051-4

[3] Eason RJ, Harding E, Nicholson R, et al. Chronic suppurative otitis media in the Solomon Islands: a prospective, microbiological, audiometric and therapeutic survey. NZMed J 1986; 99(812):812-5.

[4] Poorey VK, Iyer A. Study of bacterial flora in CSOM and its clinical significance. Indian J Otolaryngol Head Neck Surg. 2002 Apr; 54(2):91-5.

[5] Berman S. Otitis media in developing countries. Pediatrics 1995; 96:126-31.

[6] Wiwanitkit S, Wiwanitkit V. Pyogenic brain abscess in Thailand. N Am J Med Sci 2012; Wiwanit

[7] Nam EC, Kim MN, Lee KS. Surgical results of MRSA(Methicillin resistant S. aureus)isolated chronic otitis media. Korean J Otolaryngol-Head Neck Surg 1999.

[8] Bauer AW, Kirby WMM, Sherris JC, Tuck M. Antibiotics susceptibility testing by a standardized single disc method. Am J Clin Pathol 1966; 45:493-6.

[9] Clinical and Laboratory Standard Institute. 2013. Performance standards for antimicrobial susceptibility testing; 23rd informational supplement. CLSI document M100-S23. Clinical and Laboratory Standard Institute, Wayne, PA.

[10] Anand K B,Aggarwal P, Kumar S, Kapila K. Comparison of Cefoxitin Disc Diffusion test, Oxacillin screen agar and PCR for MecA gene for detection of MRSA. Indian J Med Microbiol.2009; 27(1):27-9.

[11] Sateesh Kumar Malkappa, Kondapaneni, Saileela, Surpam, Rajendra Bhanudas, Chakraverti, Trinain. Study of aerobic bacterial isolates and their antibiotic susceptibility pattern in chronic suppurative otitis media, Indian J Otol, 2012; 18(3):136-9.

[12] Sahu MC, Swain SK. Surveillance of antibiotic sensitivity pattern in chronic suppurative otitis media of an Indian teaching hospital. WJOHNS. 2019; 5(2):88-94

[13] Sawaraj S, Dogra SS, Kansal D, Thakur K, Sharma PK. Therapeutic guidelines for antimicrobial use in chronic suppurative otitis media for a tertiary care hospital in Sub Himalayan region. Int J Basic Clin Pharmacol 2018; 7:416-22.

[14] Garima, Chaurasia D, Poorey VK. Antimicrobial susceptibility pattern of bacterial isolates from chronic suppurative otitis media patients in Central India. Indian J Microbiol Res 2016;3(4):373-382.

[15] Shah Prachita J et al. MRSA in chronic suppurative otitis media. Indian Journal of Medical Research and Pharmaceutical Sciences 2017; 4(10).

[16] Prakash R, Juyal D, Negi V, Pal S, Adekhandi S, Sharma M, et al. Microbiology of chronic suppurative otitis media in a tertiary care setup of uttarakhand state, India. North Am J Med Sci 2013; 5:282-7.

[17] Prakash M, Lakshmi K, Anuraha S, Swathi GN. Bacteriological profile and their antibiotic susceptibility pattern of cases of chronic suppurative otitis media. Asian Pharm Clin Res. 2013; 6:210-12.

[18] Jevons MP. Celbenin resistant staphylococci. BMJ 1961; 1 (5219):124-5.

[19] Lowy FD. Staphylococcus aureus infections. N Engl J Med 1998; 339(8):520-32.

[20] Patigaroo SA, Wani SM, Anjum N, Islam M, Sumbrai D, Ahmad R. Drift in the bacteriology of chronic suppurative otitis media and methicillin-resistant
Staphylococcus aureus as an emerging pathogen: an experience. Int J Med Sci Public Staphylococcus aureus
Health 2016;5:671-67.

[21] Manjula.Vagrali., Soumya S and Jyoti.M.Nagmoti (2018) 'Methicillin Resistant Staphylococcus Aureus (Mrsa) As An Emerging Pathogen In Chronic Suppurative Otitis Media (Csom)', International Journal of Current Advanced Research, 07(2), pp. 10295 10297

[22] Sena RB, Pavani G. Antibiotic resistance in CSOM in a teaching hospital. J. Evolution Med. Dent. Sci. 2016; 5(61):4263-4267. 